\title{
O ENSINO DE EMPREENDEDORISMO NOS CURSOS DE GRADUAÇÃO EM ADMINISTRAÇÃO: UM ESTUDO COMPARATIVO ENTRE AS UNIVERSIDADES ESTADUAIS DE LONDRINA E MARINGÁ
}

\author{
THE TEACHING OF ENTREPRENEURSHIP IN COURSES OF \\ MANAGEMENT: A COMPARATIVE STUDY AT STATE UNIVERSITIES \\ OF LONDRINA AND MARINGA
}

Recebido - 22/03/2011

Aceito - 14/07/2011

\begin{abstract}
Saulo Fabiano Amâncio Vieira ${ }^{1}$, Gerson Antonio Melatti ${ }^{2}$ e Paula Regina Ribeiro ${ }^{3}$
\end{abstract}
\section{Resumo}

Verifica-se, atualmente, a importância do empreendedorismo no desenvolvimento econômico e social e, com isso, a necessidade de se construir uma sociedade empreendedora. O melhor caminho é através do ensino, que pode estimular e desenvolver, nos alunos, habilidades e capacidades necessárias à gestão de um empreendimento. A efetiva aprendizagem da disciplina de Empreendedorismo depende da adoção de métodos e práticas de ensino específicas, e não mais dos modelos da educação tradicional. Assim, este trabalho tem como objetivo compreender de que forma o empreendedorismo é tratado em duas das principais instituições públicas de ensino superior do Paraná. Trata-se de uma pesquisa qualitativa, exploratória e descritiva, apresentada na forma de um estudo comparativo entre as universidades estaduais de Londrina e de Maringá, ambas localizadas no Paraná. Os resultados apontam que o empreendedorismo é tratado sob diferentes enfoques em cada instituição, sendo que, na Universidade Estadual de Londrina (UEL), os métodos são mais aplicados, voltados à criação de negócios. Também se identificou relação entre o perfil do coordenador do curso e o foco dado pelo currículo à disciplina, bem como certo descompasso entre as necessidades acadêmicas e a resposta institucional para o ensino do empreendedorismo.

Palavras-chave: Empreendedorismo. Formação empreendedora. Práticas pedagógicas.

1 Doutor em Administração e professor adjunto do Departamento de Administração da Universidade Estadual de Londrina (UEL). E-mail: saulo@uel.br

2 Mestre em Administração e professor assistente do Departamento de Administração da Universidade Estadual de Londrina (UEL). E-mail: gmelatti@uel.br

3 Graduada em Administração pela Universidade Estadual de Londrina (UEL). E-mail: paulinha_regina26@hotmail.com 


\begin{abstract}
The importance of the entrepreneurship in economic and social development is verified currently with the necessity of constructing an enterprising society. An effective way is through education, that can stimulate and develop in the pupils necessary abilities and capacities to the management of an enterprise. The effective learning of disciplines of Entrepreneurship depends on the adoption of specific practical and methods of education, and not more than the models of the traditional education. Thus, this work has as objective to understand the education of entrepreneurship in public institutions of superior education of the south of the country, analyzing, among others aspects, the academic profile of the coordinators of the course of Administration and the didactic-pedagogical practices used for the education of discipline of entrepreneurship. This work is a qualitative research, presented in the form of a comparative study enters the state universities of Londrina and Maringá, both located in the Paraná. Among others aspects, the results point the trend of curricular adaptation to the new academic and market necessities, followed of the lack in the support to pedagogical practices turned to the entrepreneurship.
\end{abstract}

Keywords: Entrepreneurship. Enterprising formation. Pedagogical practices.

\title{
1 INTRODUÇÃO
}

A complexidade social e econômica que se observa de forma generalizada, no cenário global, e cuja origem pode estar na valorização do conhecimento e na globalização da economia, é responsável por criar, no universo organizacional, a necessidade de atualizações constantes, inovação, busca acirrada a diversos tipos de informação e acesso a novas tecnologias. Para enfrentar tais questões, uma alternativa que vem sendo proposta e que está encontrando respaldo na comunidade acadêmica é a disseminação da cultura empreendedora.

Muitos estudos têm sido feitos na tentativa de melhorar a compreensão sobre esse fenômeno, sendo que a importância e o crescimento desses estudos se dão pelo fato de os empreendedores significarem a força econômica de um país, representando sua riqueza e seu potencial de geração de empregos (BIRLEY; MUZYKA, 2001).

Pode-se afirmar que o conceito de empreendedorismo está, atualmente, em processo de expansão para quase todas as disciplinas das Ciências Humanas (FILION, 1999), sendo que sua disseminação pode ser entendida, principalmente, como um processo de formação de atitudes e características, e não apenas como uma forma de transmissão de conhecimento teórico (DOLABELA, 1999a). Assim, a disseminada crença de que a capacidade empreendedora é inata ao ser humano e que só pode ser herdada geneticamente começa a ser descartada do ambiente acadêmico, acreditando-se, cada vez mais, que "o processo empreendedor pode ser ensinado e entendido por qualquer pessoa" (DORNELAS, 2001, p. 38).

Pesquisas importantes têm se concentrado em discutir, e provar, que o empreendedorismo pode ser ensinado, e que os resultados da efetiva aprendizagem dependem de metodologias específicas, e não mais dos modelos da educação tradicional. Assim, para se compreender totalmente o fenômeno do empreendedorismo, é necessário que se conheça o processo de formação dos empreendedores, a fim de identificar e, a partir disso, poder promover a melhor metodologia para esse tipo de educação.

Diante disso, este artigo propõe identificar de que forma se dá o ensino de empreendedorismo como atividade integrante dos projetos pedagógicos dos cursos de graduação em Administração de duas das principais universidades estaduais do Paraná: a Universidade Estadual de Londrina (UEL) e a Universidade Estadual de Maringá (UEM). O trabalho apresenta uma revisão da literatura sobre o empreendedorismo e sobre seu ensino, os procedimen- 
tos metodológicos bem como os dados coletados das duas universidades em estudo, estando, entre eles, o perfil acadêmico dos coordenadores do curso de Administração, as práticas didático-pedagógicas utilizadas para o ensino da disciplina de empreendedorismo e a estrutura da matriz curricular. Por fim, é apresentada uma análise comparativa entre os elementos e processos observados nas duas universidades.

\section{REFERENCIAL TEÓRICO}

\subsection{O empreendedorismo e o empreendedor}

Segundo Filion (1999), o empreendedorismo compreende a área cujo objeto de estudo são os empreendedores. A palavra empreendedor tem sua origem no termo francês entrepreneur, que, literalmente traduzido, significa "aquele que está entre" ou "intermediário". Hisrich e Peters (2004) apresentam exemplos dessa definição que remetem ao período da Idade Média, em que o empreendedor assinava um contrato com uma pessoa de recursos (o atual capitalista de risco) para vender suas mercadorias. Enquanto o capitalista assumia riscos passivamente, o intermediário assumia o papel ativo do negócio, tendo de suportar seus riscos físicos e emocionais.

Foi apenas no final do século XII e início do século XIII que o termo foi usado para se referir à pessoa que criava e conduzia projetos ou empreendimentos. O entrepreneur era uma pessoa que identificava uma oportunidade de negócio e assumia seu risco, decidindo processar e revender matéria-prima. Dessa maneira, o risco apareceu nas atividades empreendedoras do século XIII. (FILION, 1999).

Os conceitos contemporâneos de empreendedorismo se desenvolveram a partir dessas definições, e percebe-se que não há limites claros em cada abordagem de estudo. Baseando-se em trabalhos de Filion (1999), pode-se afirmar que a primeira abordagem do empreendedorismo é a econômica, que busca identificar elementos inerentes aos agentes econômicos e destacar seu papel na formulação de processos inovadores em gestão e tecnologia. De acordo com Filión (1999), essa corrente é defendida por Cantillon, Schumpeter e Say, sendo que, para os dois primeiros, os empreendedores podiam ser vistos como pessoas que corriam riscos. Say distingue empreendedores e capitalistas, bem como os lucros de cada um deles e, com isso, começa a associar os empreendedores à inovação, vendo-os como agentes de mudança. Porém, conforme registra Filión (1999), foi Schumpeter quem realmente lançou o campo do empreendedorismo, associando-o, claramente, à inovação e mostrando, em sua obra, a importância dos empreendedores na explicação do desenvolvimento econômico. Para o autor, além de ser um inovador, o empreendedor é responsável por desenvolver tecnologias que ainda não foram testadas.

A segunda perspectiva apontada por Filion (1999) é a comportamental, que encontrou, na figura de David McClelland, o autor que deu início à contribuição das ciências do comportamento para o empreendedorismo. Essa perspectiva trata das responsabilidades individuais na criação e gestão de negócios, tendo como fundamento as características psicológicas e comportamentais dos empreendedores. Depois de McClelland, os comportamentalistas dominaram o campo do empreendedorismo, e, entre as características atribuídas por eles aos empreendedores, estão a inovação, liderança, criatividade, iniciativa, autoconfiança e necessidade de realização. 
Ainda, Ferreira, Ramos e Gimenez (2006) apresentam uma terceira linha de estudo sobre empreendedorismo, que se confunde muito com a segunda: a abordagem sociológica. Nesta, assim como nas anteriores, destaca-se o papel do empreendedor como inovador e criador de negócios, porém as características sociais do grupo no qual o indivíduo está inserido também são consideradas. Os autores apresentam Max Weber como o principal expoente dessa abordagem.

Entre as atuais definições, o empreendedorismo é entendido da seguinte forma:

Empreendedorismo é o processo de criar algo novo com valor dedicando o tempo e o esforço necessários, assumindo os riscos financeiros, psíquicos e sociais correspondentes e recebendo as consequentes recompensas da satisfação e independência econômica e pessoal. (HISRICH; PETERS, 2004, p. 29).

Essa definição enfatiza elementos básicos do empreendedorismo, apontados por vários estudiosos. Estão, entre eles, o processo de criação, a exigência de dedicação de tempo e esforço para se criar algo novo e passível de operacionalização e as recompensas que se apresentam em função do sucesso do empreendimento.

Segundo Dolabela (2007), uma teoria visionária foi criada e apresentada pelo canadense Louis Jacques Filion, a qual ampliou o campo da ação empreendedora ao afirmar que "um empreendedor é uma pessoa que imagina, desenvolve e realiza visões" (FILION, 1999, p. 19). Tal abordagem foi muito explorada pela escola empreendedora do pensamento estratégico, que via a formação da estratégia justamente como um processo visionário, onde o executivo principal, ao centralizar todas as ações e decisões, desempenha uma liderança empreendedora, guiada pela perspectiva e visão do futuro da organização (MINTZBERG; AHLSTRAND; LAMPEL, 2000).

O empreendedorismo também pode ser entendido como um sistema aberto e dinâmiCo, cuja finalidade é promover melhor aproveitamento dos recursos sociais, materiais e cognitivos. (FERREIRA; RAMOS; GIMENEZ, 2006). Nessa abordagem sistêmica, os recursos, a insatisfação e o agente (empreendedor) representam as entradas (inputs) que, uma vez transformadas, resultarão em inovação revestida de valor econômico (output), não precisando ser, necessariamente, algo inédito, mas um rearranjo de recursos. A retroalimentação (feedback) garante o equilíbrio dinâmico do sistema e permite constante adequação, dando significado às informações obtidas com indicadores de desempenho e de satisfação do mercado relacionado à inovação.

Frente ao que foi apresentado até agora, ressalta-se que este artigo não considera nenhuma abordagem ou definição mais importante que outra, de modo que, considerando a época e o contexto em que foram propostas e estudadas, cada uma delas teve sua utilidade e relevância. Entende-se que todos os estudos, sem exceção, contribuíram e ainda contribuem, de alguma forma, para que se chegue ao entendimento do fenômeno empreendedorismo.

Independentemente da abordagem que os estudiosos tendem a defender, o empreendedorismo tem recebido crescente atenção da comunidade acadêmica, o que gera grande volume de trabalhos e estudos que tentam explicá-lo. Uma das causas para isso talvez seja o fato de que os empreendedores, mesmo quando não possuem habilidades técnicas e gerenciais, representam a ponte entre o desenvolvimento de inovações e o crescimento econômico. É justamente essa ligação entre habilidade/capacidade empreendedora e desenvolvimento econômico/social que faz com que o estudo do empreendedorismo esteja cada vez mais atrelado ao estudo da formação empreendedora. 


\title{
2.20 ensino do empreendedorismo
}

Até poucos anos, acreditava-se que as habilidades empreendedoras de forma alguma poderiam ser ensinadas, e as pessoas que não nasciam com o "dom" empreendedor eram desaconselhadas a buscar a abertura de um empreendimento (DORNELAS, 2001). Pode-se afirmar, então, que o aumento no interesse pelos processos e metodologias de ensino do empreendedorismo teve início em estudos que questionavam esse difundido entendimento de que a capacidade empreendedora é inata ao ser humano, só podendo ser herdada geneticamente.

\begin{abstract}
[...] cada vez mais, acredita-se que o processo empreendedor pode ser ensinado e entendido por qualquer pessoa e que o sucesso é decorrente de uma gama de fatores internos e externos ao negócio, do perfil do empreendedor e de como ele administra as adversidades que encontra no dia a dia. (DORNELAS, 2001, p. 38).
\end{abstract}

Devido a essa circunstância, o empreendedorismo como disciplina foi se desenvolvendo e se moldando através de estudos e trabalhos esparsos, elaborados por pesquisadores de diversas áreas do conhecimento, impulsionados pelas necessidades do mercado.

Muitas são as recomendações e sugestões para o ensino do empreendedorismo, e parece comum o entendimento de que os métodos tradicionais de ensino não oferecem suporte ao aprendizado da disciplina, já que conteúdos muito teóricos e limitados ao ambiente da sala de aula não permitem que a formação dos potenciais empreendedores aconteça alinhada à realidade do mercado.

Esse descompasso entre o ensino tradicional e o ensino do empreendedorismo já foi observado e relatado por Filion (1999, p. 11):

\footnotetext{
É interessante notar que o desenvolvimento do empreendedorismo como disciplina não seguiu padrão semelhante ao de outras disciplinas. Na verdade, grande número de pesquisadores, cada um usando sua cultura, lógica e metodologia estabelecidos em graus variados em seus próprios campos de estudo, começou a interessar-se e a trabalhar no campo do empreendedorismo e de pequenos negócios.
}

Percebe-se, com isso, a dificuldade em se adequar o ensino do empreendedorismo com o ensino de outras disciplinas da área de Administração. Drucker (1987, p. 16) já afirmava que "Empreendimento não é nem ciência nem arte. É uma prática". Por isso, parte da base de conhecimento necessária para a execução de um empreendimento é definida pelos fins, ou seja, pela própria prática e experiência. Dessa forma, já se pode ter uma ideia das dificuldades enfrentadas por muitas instituições ao implantarem a disciplina de Empreendedorismo em seus currículos.

Essa constatação encontra respaldo em Dolabela (1999a, p. 114), segundo o qual, "para haver efetividade didática na área de empreendedorismo, é essencial que o aprendizado seja insistentemente contextualizado. [...] o aluno pré-empreendedor precisa ser submetido a situações similares àquelas que encontrará na prática".

Para Fowler (1997), a educação empreendedora é um sistema que habilita pessoas a criar e dirigir seus próprios negócios, utilizando isso como meio de aprendizagem. Assim, a capacidade empreendedora pode ser entendida como o aproveitamento de oportunidades e recursos disponíveis, englobando tanto situações de criação de um negócio como a condução de uma empresa já estabelecida. 
De acordo com Guimarães (2002), quando o objetivo é passar para os alunos informações sobre o processo de criação de empresas e sobre valores e atitudes que devem permear a prática empresarial, o ideal seriam aulas expositivas e leituras obrigatórias. Já o desenvolvimento de projetos com ação efetiva dos alunos deve ser a técnica mais utilizada quando se quiser identificar e avaliar oportunidades.

Uma terceira recomendação é em relação à fase de fundação da empresa. Os elementos essenciais nessa fase são: planejamento do negócio, captação e organização de recursos, desenvolvimento de uma rede de apoio e desenvolvimento de estratégias. Dessa forma, a metodologia precisa estimular a elaboração de projetos através de orientação docente e interação entre grupos.

Em relação ao conteúdo, as recomendações convergem, ao apontar elementos relacionados às habilidades para identificar oportunidades e avaliar negócios, lidar com riscos e incertezas e adquirir conhecimentos técnicos que permitam criar e gerenciar novos negócios. Para o ensino do empreendedorismo, os métodos mais sugeridos são aqueles orientados para a ação, baseados na experiência e dominados por um caráter vivencial. Ferreira, Ramos e Gimenez (2006) afirmam que muitos estudos na área do ensino do empreendedorismo apontam para a necessidade de aprimoramento dos professores em todos os níveis da educação, a fim de que se construa um ambiente empreendedor, que envolva os alunos.

Considerando o contexto brasileiro, Dolabela (1999b) registra que o ensino do empreendedorismo é um fenômeno recente, sendo que o primeiro curso na área, de que se tem notícia, surgiu em 1981, na Escola de Administração de Empresas da Fundação Getúlio Vargas (São Paulo-SP), fazendo parte de um programa de pós-graduação. Apenas três anos mais tarde, em 1984, o curso foi estendido para a graduação.

No Brasil, os cursos de graduação em Administração, tradicionalmente, organizam seus currículos visando à formação de profissionais que atuem como gerentes em grandes organizações, esquecendo-se da realidade das pequenas e médias empresas nacionais. Tendo em vista que as oportunidades de trabalho crescem nas pequenas e médias empresas e decrescem nas grandes organizações, essa carência acadêmica dificultaria a atuação profissional nesse cenário. (DOLABELA, 1999a).

A educação tradicional está voltada para a formação de empregados, fazendo com que os recém-formados no curso de Administração procurem empregos em cargos gerenciais ou intermediários, na área administrativa de empresas já consolidadas. Essa situação negligencia o aprendizado do grande desafio, que é a capacidade de inovar e de se adequar às tendências e oportunidades mundiais de negócios.

Dolabela (1999b, p. 7) apresenta algumas sugestões para o ensino de empreendedorismo. Entre elas, destaca-se:

\footnotetext{
1) Propagar o ensino de empreendedorismo para todos os níveis educacionais;

2) Estimular a pesquisa na área de empreendedorismo;

3) Estimular o empreendedor científico;

4) Estimular a criação de incubadoras e parques tecnológicos científicos.
}

Aparentemente, criar uma sociedade orientada ao empreendedorismo, baseada na formação empreendedora, não é uma tarefa fácil, mas este parece ser o caminho para o desenvolvimento em todos os níveis econômicos e sociais. 


\section{PROCEDIMENTOS METODOLÓGICOS}

Em relação ao seu delineamento, esta pesquisa se caracteriza como qualitativa, descritiva e exploratória, sendo desenvolvida por meio de estudo de caso múltiplo. Em uma pesquisa qualitativa, o pesquisador deve ir a campo, buscando "captar" o fenômeno em estudo, a partir da perspectiva das pessoas nele envolvidas, considerando todos os pontos de vista relevantes (GODOY, 1995). O caráter exploratório se deve ao desejo de se identificar de que forma se dá o ensino do empreendedorismo como atividade integrante dos projetos pedagógicos dos cursos de graduação em Administração de duas das principais universidades estaduais do Paraná: a Universidade Estadual de Londrina (UEL) e a Universidade Estadual de Maringá (UEM). Para esse fim, foi utilizado o método de pesquisa qualitativa, desenvolvendo um estudo de caso, conforme os parâmetros preconizados por Yin (2001).

O caso escolhido para o estudo e aprofundamento, nesta investigação, foi o curso de administração da UEL e da UEM, mais precisamente a chefia do colegiado de curso, cargo responsável pela gestão pedagógica dos cursos. Sua escolha foi feita de forma intencional, levando-se em consideração a facilidade de acesso e a importância dessas instituições dentro do sistema estadual de ciência e tecnologia.

Foram realizadas entrevistas com os coordenadores de colegiado de curso das referidas instituições, por meio de um roteiro de entrevistas semiestruturado, focado e composto por 34 questões. Ao término das entrevistas, foi realizada a transcrição dos dados, bem como a análise das informações coletadas, basicamente de caráter qualitativo. Todas as considerações relevantes obtidas através da análise documental foram registradas nas páginas de anotação de campo, sendo complementando as informações obtidas nas entrevistas. Os resultados obtidos a partir das entrevistas e da análise documental foram, inicialmente, verificados caso a caso, ou seja, por cada pergunta. Em seguida, a análise foi agrupada, no sentido de responder ao objetivo da pesquisa.

\section{DESCRIÇÃO DOS RESULTADOS}

\subsection{Universidade Estadual de Londrina}

O curso de Administração dessa universidade foi criado em 1969 e, pelo currículo vigente, cuja implementação ocorreu a menos de cinco anos, tem duração de quatro anos, sendo que o currículo possui formato seriado semestral, em que cada semestre corresponde a uma série do curso. Há uma disciplina específica, obrigatória e essencial de empreendedorismo em sua grade curricular, a qual é ofertada no $2^{\circ}$ ano ( $3^{\circ}$ e $4{ }^{\circ}$ semestres, conforme grade curricular) do curso, e possui carga horária total de 102 horas, dividida em 34 horas teóricas e 68 horas práticas.

A coordenadora do curso é uma mulher com idade entre 46 e 60 anos, cuja titulação é a de Mestre. Seus estudos de pós-graduação, com ênfase na área de Marketing, foram realizados na Universidade Norte do Paraná (Londrina, PR), tendo os concluído em 2000. Durante tal formação, ela cursou disciplina de empreendedorismo.

A coordenadora concorda que o empreendedorismo seja fundamental para a formação de um empreendedor, bem como que as características individuais de um empreendedor possam ser ensinadas pela educação formal. Também acredita que todas as áreas da Administração possuem mesmo grau de importância para o ensino do empreendedorismo. 
A instituição está relativamente bem estruturada no tocante às entidades e aos programas voltados para o empreendedorismo, uma vez que possui quase todos os que foram elencados no instrumento de pesquisa: consultoria Júnior, programas de estágio voluntário, trabalho de conclusão de curso, bem como projetos ou programas de pesquisa vinculados, ou orientados, ao empreendedorismo.

Considerando o trabalho de conclusão de curso, verificou-se a existência de uma modalidade específica, voltada para a criação de empresa, elaboração de plano ou reciclagem de um negócio. Tal trabalho só pode ser desenvolvido individualmente e deve ser apresentado a uma banca examinadora composta apenas por professores do curso.

O curso não faz nenhum tipo de acompanhamento a fim de saber se ocorre a abertura de negócios próprios (criação de empresas) por parte dos graduandos ou dos egressos recentes. Em relação aos recursos disponíveis para o ensino da disciplina de empreendedorismo, a instituição possui computadores, acesso à internet, retroprojetor, datashow e acervo de livros, e todos são, efetivamente, utilizados para o ensino da disciplina. As práticas pedagógicas de ensino do empreendedorismo são afetadas, principalmente, pela falta de uma ferramenta de análise econômico-financeira. Quanto ao tamanho das turmas, afirmou-se que ele é inadequado à proposta de ensino e ao nível de dedicação dos docentes: no momento da pesquisa, cada turma possuía mais de 40 alunos, sendo que o ideal sugerido é de 11 a 20 alunos, o que significa que as salas de aula possuem o dobro de alunos do que o indicado.

Considerando-se a infraestrutura da UEL, constatou-se que ela não atende a todas as práticas utilizadas pelos docentes em sala de aula. A coordenadora do curso acredita que melhorias na infraestrutura da instituição seriam fundamentais para o aprimoramento das práticas de ensino de empreendedorismo. Assim, os itens que a instituição não possui, mas que seriam essenciais para o ensino de empreendedorismo são: biblioteca com mais títulos, laboratório de informática específico para a disciplina e espaço para um centro de empreendedorismo.

Ao investigar as práticas pedagógicas existentes para o ensino do empreendedorismo, identificou-se que são utilizadas aulas expositivas, trabalhos teóricos individuais, trabalhos teóricos em grupo, livro-texto, provas dissertativas, estudos de caso, depoimentos de empreendedores convidados, trabalhos práticos em grupo, palestras com executivos e empresários convidados, seminários apresentados pelos alunos, plano de negócios e atendimento individualizado.

\subsection{Universidade Estadual de Maringá}

O curso de Administração foi criado em 1971. Pelo currículo vigente, tem duração de quatro anos, mas passará a ter cinco para os ingressantes a partir de 2010, já que há menos de um ano houve alteração curricular. O currículo possui formato seriado anual, em que cada ano corresponde a uma série do curso. Há uma disciplina específica e obrigatória de empreendedorismo na grade curricular, a qual é ofertada no 40 ono do curso (último ano) e possui carga horária apenas teórica, de 68 horas.

A coordenadora do curso é uma mulher jovem, de até 30 anos, cuja titulação é a de Mestre. Ela cursou o programa de pós-graduação na Universidade Estadual de Londrina, com ênfase na área de Teoria Organizacional, tendo o concluído em 2005. Durante tal formação, cursou uma disciplina de empreendedorismo.

Embora concorde que o empreendedorismo seja fundamental para a formação de um empreendedor, a coordenadora afirma que as características individuais de um empreendedor não podem ser ensinadas pela educação formal. Também acredita que todas as áreas da Administração possuem mesmo grau de importância para o ensino do empreendedorismo. 
No tocante às entidades e aos programas voltados para o empreendedorismo, a instituição está muito bem estruturada, uma vez que possui todos os que foram elencados no instrumento de pesquisa. Além dos já citados para a UEL, há também a consultoria Júnior.

O trabalho de conclusão de curso na UEM é feito da mesma forma que na UEL, e o acompanhamento de graduandos e egressos quanto à abertura de empresas também é inexistente.

O curso não faz nenhum tipo de acompanhamento a fim de saber se ocorre a abertura de negócios próprios (criação de empresas) por parte dos graduandos ou dos egressos recentes. Em relação aos recursos disponíveis para o ensino da disciplina de empreendedorismo, a instituição possui computadores, acesso à internet, datashow e acervo de livros, mas foi afirmado que o datashow, apesar de estar à disposição, não é efetivamente utilizado para o ensino da disciplina. As práticas pedagógicas de ensino de empreendedorismo não são afetadas pela falta de nenhuma ferramenta ou recurso de ensino.

Quanto ao tamanho das turmas, ocorre o mesmo problema verificado na UEL: atualmente, cada turma possui entre 31 e 40 alunos, enquanto o ideal seria um número que estivesse entre 21 e 30 alunos, o que significa que hoje há um excedente de 10 alunos por sala.

Considerando-se a infraestrutura da UEM, constatou-se que ela também não atende a todas as práticas utilizadas pelos docentes em sala de aula. A coordenadora do curso acredita que melhorias na infraestrutura da instituição seriam fundamentais para o aprimoramento das práticas de ensino de empreendedorismo. Assim, os itens que a instituição não possui, mas que seriam essenciais para o ensino de empreendedorismo, são as salas de aula em quantidade, tamanho e comodidade adequados, bem como a possibilidade de se efetuar visitas técnicas a empresas.

As práticas pedagógicas existentes para o ensino do empreendedorismo na na UEL também são utilizadas na UEM, onde há, ainda, o desenvolvimento de produto.

\subsection{Formação empreendedora: análise comparativa dos resultados}

Ao analisar os dados colhidos nas duas instituições de ensino, pode-se perceber que ambas estão sob processo de mudança curricular, sendo que na UEL um novo currículo foi implantado em 2006, e na UEM a implantação de novo currículo estava prevista para 2010. Esse cenário permite concluir que há uma tentativa de adaptação das instituições, através de seus currículos, às novas tendências e exigências tanto acadêmicas quanto mercadológicas. Ressaltase que, para este trabalho, foram considerados apenas os currículos atualmente em vigência em cada universidade.

Considerando a estrutura curricular, a disciplina de empreendedorismo possui nítidas peculiaridades em cada uma das instituições. Suas características gerais podem ser observadas no quadro 1.

Na UEL, a disciplina de empreendedorismo está alocada dentro de um módulo chamado Módulo de Criação e Reciclagem de Negócios (MCRN), em que todas as disciplinas estão dispostas de forma a possibilitar o estudo, a compreensão conceitual e o domínio do ferramental técnico da formatação, avaliação e inserção competitiva dos negócios no ambiente.

Com base no quadro 1, constata-se que a disciplina de empreendedorismo da UEL possui maior nível de complexidade, sendo dividida em duas fases, uma teórica e outra prática, com objetivos bem definidos e maior tempo de duração, uma vez que se desenvolve durante todo o 2 a ano do curso.

Vale acrescentar que, entre os procedimentos e as análises que os alunos precisam elaborar durante a fase prática da disciplina de empreendedorismo da UEL, eles devem levar 


\begin{tabular}{|c|c|c|}
\hline Item/Instituição & UEL & UEM \\
\hline Nome da disciplina & $\begin{array}{l}\text { Empreendedorismo e Elaboração de Projetos } \\
\text { de Negócios I e II }\end{array}$ & Empreendedorismo \\
\hline Carga horária (h) & $\begin{array}{l}\text { Teórica: } 34 \text { (I) } \\
\text { Prática: } 68 \text { (II) }\end{array}$ & Teórica: 68 \\
\hline Período de oferta & $2^{\circ}$ ano & 40 ano \\
\hline Tempo de duração & 1 ano & 1 semestre \\
\hline Objetivos & $\begin{array}{l}\text { (I) Estudar o surgimento e evolução do } \\
\text { empreendedorismo bem como as } \\
\text { características do empreendedor. Identificar } \\
\text { oportunidades de negócios e estruturar o } \\
\text { plano de negócio. } \\
\text { (II) Prática de desenvolvimento de projeto de } \\
\text { criação e/ou reformatação de negócio, } \\
\text { abrangendo todos os procedimentos e } \\
\text { análises necessárias à abertura de uma } \\
\text { empresa. }\end{array}$ & $\begin{array}{l}\text { Apresentar o processo } \\
\text { empreendedor, o ciclo de vida das } \\
\text { organizações e as características do } \\
\text { comportamento empreendedor. } \\
\text { Elaborar plano de negócios e } \\
\text { estudar sobre empresas familiares. }\end{array}$ \\
\hline
\end{tabular}

Quadro 1 - Aspectos curriculares

Fonte: dados da pesquisa.

em conta: viabilidade mercadológica, dimensionamento e análise de viabilidade técnica e financeira e procedimentos legais para abertura de uma empresa. Tais práticas não ocorrem na UEM, cuja ementa é mais simples, com menor carga horária e conteúdos apenas teóricos.

Na UEM, a disciplina não está inserida em um módulo com objetivos conceituais e acadêmicos bem definidos, uma vez que pretende oferecer aos alunos uma noção teórica das habilidades e capacidades necessárias a um empreendedor. Porém, pelo fato de os alunos estarem no último ano do curso, infere-se que eles possuam maior maturidade intelectual e capacidade de assimilar o aspecto interdisciplinar do empreendedorismo.

A fim de entender melhor como ocorre o desenvolvimento da disciplina em sala de aula, elaborou-se o quadro 2.

\begin{tabular}{|c|c|c|}
\hline $\begin{array}{l}\text { Instituição de } \\
\text { ensino }\end{array}$ & \multirow[t]{2}{*}{ UEL } & \multirow[t]{2}{*}{ UEM } \\
\hline Variável avaliada & & \\
\hline $\begin{array}{l}\text { Metodologias de } \\
\text { ensino }\end{array}$ & $\begin{array}{l}\text { 1) Aulas expositivas; } \\
\text { 2) Trabalhos teóricos individuais e em } \\
\text { grupo; } \\
\text { 3) Adoção de livro-texto; } \\
\text { 4) Aplicação de provas dissertativas; } \\
\text { 5) Estudos de caso; } \\
\text { 6) Depoimentos de empreendedores } \\
\text { convidados; } \\
\text { 7) Trabalhos práticos em grupo; } \\
\text { 8) Palestras com executivos e empresários } \\
\text { convidados; } \\
\text { 9) Apresentação de seminários pelos } \\
\text { alunos; } \\
\text { 10) Elaboração de um plano de negócios; } \\
\text { 11) Atendimento individualizado. }\end{array}$ & $\begin{array}{l}\text { 1) Aulas expositivas; } \\
\text { 2) Trabalhos teóricos individuais e em } \\
\text { grupo; } \\
\text { 3) Adoção de livro-texto; } \\
\text { 4) Aplicação de provas dissertativas; } \\
\text { 5) Estudos de caso; } \\
\text { 6) Palestras com executivos e empresários } \\
\text { convidados; } \\
\text { 7) Apresentação de seminários pelos } \\
\text { alunos; } \\
\text { 8) Solicitação de desenvolvimento de } \\
\text { produto; } \\
\text { 9) Elaboração de um plano de negócios; } \\
\text { 10) Atendimento individualizado. }\end{array}$ \\
\hline
\end{tabular}

Quadro 2 - Comparação entre as metodologias de ensino

Fonte: elaborado pelos autores. 
Verifica-se que, na UEL, os métodos de ensino são de caráter mais aplicado, sendo que há desenvolvimento de trabalhos práticos em grupo (item 7), e, inclusive, o próprio currículo dá suporte para este tipo de atividade, já que apresenta, além de 34 horas de aula teórica, carga horária prática de 68 horas. Essa situação não ocorre na UEM, que possui 68 horas de aula teórica. Observa-se também que a UEL, além de oferecer palestras com executivos e empresários convidados, também apresenta aos alunos depoimentos de empreendedores, a fim de que se possa ver e avaliar casos reais, o que aproxima o mercado empreendedor da sala de aula.

Por outro lado, durante as aulas de empreendedorismo da UEM, uma das atividades praticadas é a solicitação de desenvolvimento de um produto (item 8), metodologia que não está relacionada aos processos de planejamento e criação de uma nova empresa, mas sim à criação e ao desenvolvimento de um bem ou um serviço. Salienta-se que, na UEL, tal metodologia está alocada em uma disciplina de marketing, e não de empreendedorismo.

Considerando-se as três recomendações apontadas por Guimarães (2002) para o ensino do empreendedorismo, as duas primeiras, aulas expositivas e leituras obrigatórias, são identificadas tanto na UEL quanto na UEM, as quais adotam também o desenvolvimento de planos de negócio como metodologias de ensino. No entanto, em relação à terceira recomendação, que envolve a necessidade de elaboração de projetos de criação e/ou reformatação de negócios, esta só foi identificada na UEL, cujos objetivos e ementa demandam tais atividades. Essa necessidade não ocorre no currículo da UEM, que é mais teórico.

Os aspectos relacionados à infraestrutura, ou seja, recursos que dão apoio às metodologias da sala de aula e recursos e programas institucionais voltados, ou orientados, para o empreendedorismo, podem ser observados no quadro 3.

\begin{tabular}{|c|c|c|}
\hline $\begin{array}{l}\text { Instituição de ensino } \\
\text { Variáveis avaliadas }\end{array}$ & UEL & UEM \\
\hline Recursos disponíveis & $\begin{array}{l}\text { 1) Computadores; } \\
\text { 2) Acesso à internet; } \\
\text { 3) Retroprojetor; } \\
\text { 4) Datashow; } \\
\text { 5) Acervo de livros. }\end{array}$ & $\begin{array}{l}\text { 1) Computadores; } \\
\text { 2) Acesso à internet; } \\
\text { 3) Datashow; } \\
\text { 4) Acervo de livros. }\end{array}$ \\
\hline $\begin{array}{l}\text { Programas ou entidades voltadas } \\
\text { para o empreendedorismo }\end{array}$ & $\begin{array}{l}\text { 1) Consultoria Júnior; } \\
\text { 2) Programas de estágio voluntário; } \\
\text { 3) Trabalho de conclusão de curso; } \\
\text { 4) Projetos ou programas de } \\
\text { pesquisa. }\end{array}$ & $\begin{array}{l}\text { 1) Empresa Júnior; } \\
\text { 2) Consultoria Júnior; } \\
\text { 3) Programas de estágio voluntário; } \\
\text { 4) Trabalho de conclusão de curso; } \\
\text { 5) Projetos ou programas de } \\
\text { pesquisa. }\end{array}$ \\
\hline
\end{tabular}

Quadro 3 - Recursos e programas de ensino

Fonte: elaborado pelos autores.

Observa-se que a UEM possui recursos pedagógicos utilizados em menor grau, como, por exemplo, o datashow, que foi apontado como não sendo, efetivamente, usado em sala de aula. Problemas nesse sentido também ocorrem na UEL, que possui mais recursos, embora eles não sejam suficientes ou adequados: são poucos computadores e o acervo de livros precisaria ser melhor e maior.

Porém, também pode ser observado, no quadro 3, que a UEM possui mais programas voltados para o empreendedorismo. A carência da UEL nesse sentido pode ser comprovada pelas observações feitas por sua própria coordenadora de curso: 
Penso que para termos bons resultados com a disciplina seria fundamental a existência do Centro de Empreendedorismo ou Escola de Negócios, desenvolvimento de protótipos de negócios, incubação de ideias, etc. A Inserção de Sessões de Simulações principalmente nas áreas de marketing, produção, finanças e projetos organizacionais

Percebe-se que há certo descompasso entre a abordagem que se dá à disciplina de empreendedorismo e a resposta institucional. Claramente, a UEL se propõe a alinhar a formação empreendedora com as reais necessidades de mercado, conforme se observa no currículo do curso. Porém, os recursos, as ferramentas e a infraestrutura encontrada não dão total suporte para que as intenções propostas pelo currículo sejam efetivamente praticadas pelos alunos. Em relação à UEM, nota-se que seu currículo é mais bem apoiado pelas condições oferecidas pela universidade. Com isso, o ensino da disciplina de empreendedorismo é mais eficiente, respondendo melhor a seus objetivos e a sua ementa.

Considerando a infraestrutura oferecida aos alunos, ambas as instituições são carentes em algum aspecto. É interessante notar que o número de alunos por sala de aula é muito superior ao que as coordenadoras consideram ideal para as aulas de empreendedorismo. Na UEL, há um excedente de 20 alunos por sala, e na UEM de cerca de 10. A situação precária é confirmada pelas duas coordenadoras quando afirmam que melhorias na infraestrutura seriam fundamentais para que houvesse melhoria nas práticas de ensino do empreendedorismo. Outra carência encontrada nas duas instituições é em relação a visitas técnicas a empresas: levar os alunos a campo, para que observem a realidade fora da sala de aula, foi apontado como uma prática que seria fundamental, mas impossibilitada pela atual estrutura das universidades.

É importante notar que as coordenadoras das duas instituições participaram da elaboração da matriz curricular de seus cursos, sendo que, na UEL, essa participação se limitou à primeira fase da construção do currículo. Constatou-se forte ligação entre o perfil acadêmico do coordenador de curso e a ênfase dada à disciplina de empreendedorismo pelo currículo. Na UEM, a disciplina possui característica mais teórica, estando a formação acadêmica da coordenadora do curso, que teve ênfase justamente em Teoria Organizacional, alinhada a este fato.

Já na UEL, a coordenadora do curso tem formação em Marketing, área da Administração que, por estar voltada para as necessidades de um mercado em potencial ou em expansão, pode permitir também maior ênfase em atividades empreendedoras. Tal fato pode ser inferido através da presença de um currículo elaborado de tal forma que reserva maior carga horária para a disciplina de empreendedorismo, colocando-a como eixo central das atividades desenvolvidas durante todo o $2 \mathrm{o}$ ano do curso e englobando objetivos mais práticos.

Pode-se afirmar ainda que as duas instituições demonstram preocupação em melhorar a formação empreendedora oferecida aos alunos e têm consciência, agindo sob essa perspectiva, de que a universidade é a principal contribuinte para a construção de uma sociedade orientada ao empreendedorismo.

\section{CONSIDERAÇÕES FINAIS}

Esta pesquisa buscou identificar de que forma se dá o ensino de empreendedorismo como atividade integrante dos projetos pedagógicos dos cursos de graduação em Administração de duas das principais universidades estaduais do Paraná: a Universidade Estadual de Londrina e a Universidade Estadual de Maringá. 
O levantamento de dados mostrou que as metodologias de ensino mais utilizadas abordam temas relacionados ao planejamento e à criação de empresas, estando a disciplina de empreendedorismo, na UEL, inserida em um contexto mais amplo de seu projeto pedagógico e sendo um dos eixos temáticos da matriz curricular.

Assim, confrontando a afirmação de Dolabela (1999a), segundo a qual, no Brasil, os cursos de graduação em Administração organizam, tradicionalmente, seus currículos visando à formação de gerentes para grandes organizações, constatou-se que se inicia um processo de formação de empreendedores que, com senso de inovação e orientados para as reais necessidades do mercado, são capazes de planejar e criar empresas.

Ao analisar os dados colhidos nas duas instituições de ensino, percebeu-se que ambas estavam sob processo de mudança curricular, sendo que na UEL um novo currículo foi implantado em 2006, e na UEM a implantação de novo currículo estava prevista para 2010. O fato de as instituições estarem passando por alterações curriculares demonstra a conscientização de que a complexidade em que o ambiente empresarial se encontra atualmente precisa ser sustentada por uma educação alinhada às novas demandas, e já se começa a perceber a construção de uma sociedade empreendedora como uma das soluções.

Complementando Ferreira, Ramos e Gimenez (2006), pode-se afirmar que, além da necessidade de aprimoramento dos professores em todos os níveis da educação para que se construa um ambiente empreendedor, é necessário também o aprimoramento da infraestrutura e dos recursos pedagógicos institucionais. Isso porque não há como atingir todas as metas e os objetivos da disciplina de empreendedorismo, com possíveis prejuízos à aprendizagem e formação intelectual dos alunos, se não houver resposta em termos de apoio e suporte às técnicas e metodologias de ensino por parte da instituição.

A constatação de relação entre o perfil acadêmico do coordenador do curso e a abordagem curricular dada pelo currículo à disciplina de empreendedorismo é de vital importância. Isso porque se comprovou que a formação dos coordenadores e, possivelmente, a dos docentes também, influenciará a abordagem dada à disciplina em sala de aula, bem como os métodos de ensino utilizados. Conclui-se, desse modo, que é preciso que se ensine cada vez mais a cultura empreendedora, pensando que as futuras gerações serão capacitadas e habilitadas com base no conhecimento que os mestres adquirem hoje.

\section{REFERÊNCIAS BIBLIOGRÁFICAS}

\author{
BIRLEY, S.; MUZYKA, D. Dominando os desafios \\ do empreendedor. São Paulo: Makron, 2001.
}

DOLABELA, F. Oficina do empreendedor. São Paulo: Cultura, 1999a.

DOLABELA, F. O ensino de empreendedorismo: panorama brasileiro, 1999b. Disponível em: < http:/ /www.epa.adm.br/empreend003.htm>. Acesso em: maio 2009.
DOLABELA, F. Ensino de empreendedorismo na Educação Básica como instrumento do desenvolvimento local e sustentável: a metodologia pedagogia empreendedora. Revista Factus, Taboão da Serra, 2007. Disponível em: <http://www.fts.com.br/fts/ revistas/factus2/1Adm-Ensino.pdf $>$. Acesso em: 12 jun. 2009.

DORNELAS, J. C. Empreendedorismo. Rio de Janeiro: Campus, 2001.

DRUCKER, Peter F. Inovação e espírito empreendedor: prática e princípios. 6. ed. São Paulo: Pioneira, 1987. 
FERREIRA, J. M.; RAMOS, S. C.; GIMENEZ, F. A. Estudo comparativo das práticas didático-pedagógicas do ensino de empreendedorismo em universidades brasileiras e norte-americanas. Revista Alcance, UNIVALI, v. 13 , n. 2, p. 207-225, maio/ago. 2006.

FILION, L. J. Empreendedorismo: empreendedores e proprietários-gerentes de pequenos negócios. Revista de Administração, São Paulo, v. 34, n. 2, p. 5-28, abr./jun. 1999.

FOWLER, F. R. Programas de desenvolvimento de empreendedorismo: um estudo de caso: FEA-USP e DUBS. 1997. 101 f. Dissertação (Mestrado em Administração)-Faculdade de Economia e Administração, Universidade de São Paulo, São Paulo, 1997.

GODOY, A. S. Pesquisa qualitativa: tipos fundamentais. Revista de Administração de Empresas, São Paulo, v. 35, n. 3, p. 20-29, mai./jun. 1995.
GUIMARÃES, L. de O. Empreendedorismo no currículo dos cursos de graduação e pós-graduação em Administração: análise da organização didático-pedagógica destas disciplinas em escolas de negócios norte-americanas. In: ENCONTRO NACIONAL DA ASSOCIAÇÃO NACIONAL DOS CURSOS DE PÓSGRADUAÇÃO EM ADMINISTRAÇÃO, 26., 2002, Atibaia. Anais... Atibaia: Enanpad, 2002.

HISRICH, R.; PETERS, M. Empreendedorismo. 5. ed. Porto Alegre: Bookman, 2004.

MINTZBERG, H.; AHLSTRAND, B.; LAMPEL, J. Safári de estratégia: um roteiro pela selva do planejamento estratégico. Porto Alegre: Bookman, 2000.

YIN, R. K. Estudo de caso: planejamento e métodos. Porto Alegre: Bookman, 2001. 